\title{
Water Quality of the Seyfe Lake Basin, Turkey
}

\author{
Sultan Kiymaz ${ }^{\text {a }}$, William F. Bleam ${ }^{\mathrm{b}}$ \\ aLand and Water Resources, University of Kırşehir Ahi Evran, Kırşehir, \\ TURKEY \\ ${ }^{\mathrm{b}}$ Department of Soil Science, University of Wisconsin-Madison, Madison, \\ WI 53706, USA \\ Corresponding author: Sultan Kiymaz (Email address: \\ skiymaz@ahievran.edu.tr)
}

\begin{abstract}
Seyfe Lake is an important part of the natural ecosystem of Central Anatolia and lies within a $1487 \mathrm{~km}^{2}$ closed basin. Groundwater withdrawal for irrigation and recent climatic change have caused lake area to decrease for decades and to completely disappear briefly in August 2008. Groundwater quality is crucial for sustainable irrigation in the Seyfe Basin. A key finding of this study is the difference in the Hardie-Eugster alkalinity-to-calcium ratio of the lake water and that of most groundwater wells in the basin. This difference in the chemical signature of Seyfe Lake and basin groundwater means the evaporative salinization pathway of most groundwater discharged into the lake cannot account for the composition of Seyfe Lake. The ratio of actual evapotranspiration to precipitation will increase under current climate change projections. A second finding, with implications for soil salinization, is that most groundwater in Seyfe Basin has a Hardie-Eugster alkalinity-tocalcium ratio greater than unity, meaning soil alkalization will accompany soil salinization.
\end{abstract}

KEYWORDS: Electrical Conductivity, Sodium Adsorption Ratio, Salinity, Sodicity, Groundwater Chemistry, Surface Water Chemistry, Irrigation Water Quality 


\section{Introduction}

\subsection{Ramsar UNESCO Wetlands Convention}

Wetlands play a crucial role in regulating the global climate, maintaining the global hydrological cycle, preserving ecosystem diversity, and protecting human well-being [1]. Because of human activities and natural factors such as population increase, urbanization, and climate change, wetland area in the world has been decreasing and wetland quality has been deteriorating $[2-7]$.

Until recently, it has been recognized that wetlands not only contain the value of biodiversity and as habitats for plant animal and fish species, but also can bring many environmental services or functions $[1,8]$. Thus, wetland policy has begun to shift from encouraging development to protecting and rational utilization. In the context of cognition transformation, the Ramsar Convention signed in 1971 in Iran [8, 9].

\subsection{Seyfe Lake Wetlands}

There are few studies relating to the quality of surface and ground water of Seyfe Lake and the surrounding basin [7, 10-12]. This study consists of the following parts: 1) soil-water balance estimate based on potential and actual evapotranspiration using available data, 2) groundwater salinity assessment, 3) chemical evaluation of Seyfe Lake and surrounding groundwater and 4) an interpretation of groundwater discharge into Seyfe Lake based on the chemical characteristics of available groundwater data. From these results we can assess irrigation water quality of surface and groundwater sources in the Seyfe Basin.

\section{Methods and Materials}

\subsection{Seyfe Basin Study Site}

Seyfe Lake, located in the Kırşehir Province of the Central Anatolia Region, Turkey, is situated at an average altitude of $1110 \mathrm{~m}$, between $39^{\circ} 18^{\prime} \mathrm{N}$ latitude and $34^{\circ} 23^{\prime} \mathrm{E}$ longitude (Figure 1) [13]. The climate is semi-arid and continental (Koppen-Geiger climate classification Csb). Summers in the area are warm and droughty; winters are cold and precipitation. Average temperatures range between 9.5 and $11.4{ }^{\circ} \mathrm{C}$. It has an average annual precipitation in the range of $270-450 \mathrm{~mm}[13,14]$. Seyfe Lake is shallow with an average 


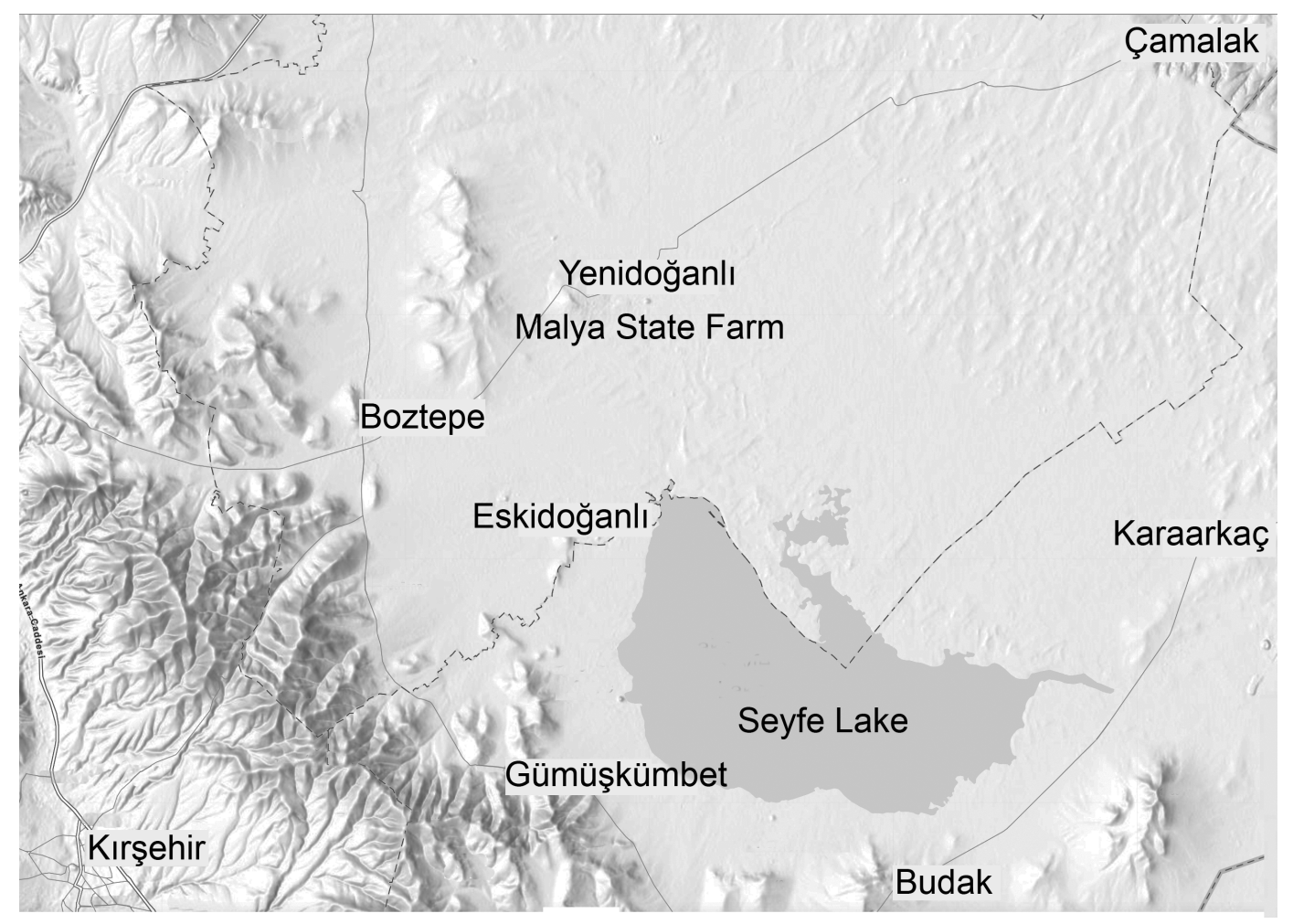

Figure 1: Relief map of Seyfe Lake and surroundings. Note the city of Kırşehir (lower left), village of Çamalak (upper right) and the village of Karaarkaç (center right). 
water depth of $1.50 \mathrm{~m}$ [15]. Groundwater in the basin serves as the main water source of irrigation and drinking.

Seyfe Lake is fed by the springs in the west and northwest of the lake, bottom springs, and runoff in the drainage area, groundwater discharge and rainfall on the lake surface. The most important springs feeding the lake are Seyfe, Horla and Yenidoğanlı springs [7, 12].

\subsection{Lake Water Samples}

Surface water samples from eleven sampling (stations) points were collected monthly from January to December 2009 [12]. The sampling locations were determined by considering locations in-lake, the springs that feed the lake and the settlements around the lake. The water sampling stations and details on sample analysis appear in [12].

\subsection{Groundwater Data}

The General Directorate of State Hydraulic Works, Turkey (Devlet Su

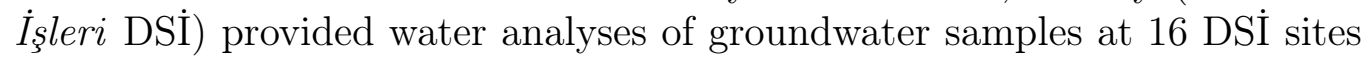
throughout the basin during the interval from 2006 to 2019. The analyses included major ions $\left(\mathrm{Ca}^{2+}, \mathrm{Mg}^{2+}, \mathrm{Na}^{+} . \mathrm{K}^{+}, \mathrm{HCO}_{3}^{-}, \mathrm{Cl}^{-}, \mathrm{SO}_{4}^{2-}\right)$ and general physicochemical parameters ( $\mathrm{pH}, \mathrm{EC}, \mathrm{TDS})$. In this study, standard analytical procedures recommended by the Examination of Water and Wastewater [16] were followed and analyzes were performed in the DSI laboratory in Kayseri, Turkey. The locations and salinity of the 16 DSI wells appears in Table 2 .

\subsection{Weather Data}

The General Directorate of Meteorology (Meteoroloji Genel Müdürlüğü MGM) provided daily precipitation and daily mean temperatures for MGM weather station 17160 at Kırşehir, located just outside Seyfe Basin, for the interval 1995-2015 (personal communication).

\subsection{Stream Discharge}

Table 1 lists the stream locations used to estimate hydrologic actual evapotranspiration AET in Seyfe Basin. The General Directorate of State Hydraulic Works (DSI) lists daily stream discharge data in annual reports from 1959 to 2012 [15]. 
Table 1: General Directorate of State Hydraulic Works DSİ streams and gage locations [15]. Gage locations are identified by UTM coordinates in Zone 36S.

\begin{tabular}{|c|c|c|c|c|}
\hline Stream & Site Identifier & Site Name & UTM Easting & UTM Northing \\
\hline & & & $m$ & $m$ \\
\hline Kalaycık & $15-108$ & near Doyduk Kozaklı & 651180 & 4339444 \\
\hline Kılıçözü & $15-152$ & above Çoğun Reservoir & 590228 & 4356603 \\
\hline
\end{tabular}

\section{Results}

\subsection{Seyfe Basin Climate and Soil Water Balance}

Recent climate projections [17] anticipate higher temperatures and lower precipitation in Central Anatolia, Turkey. Higher temperatures during the growing season and lower annual precipitation will further narrow the difference between annual precipitation in Seyfe basin and soil water loss, meaning there is little prospect that the reduction in the volume of Seyfe Lake will stabilize or reverse if current practices continue.

The Thornthwaite [18] model relies on monthly mean temperatures to estimate potential evapotranspiration. These data are available from several weather stations in and surrounding Seyfe basin. Using these data Güneş [19] estimated the annual potential evapotranspiration at seven locations (Aksaray, Avanos, Çiçekdagi. Kaman. Kırşehir, Nevşehir and Ürgüp) to be $68 \pm 3 \mathrm{~cm}$ per annum. Our estimate of potential evaporation using the tenyear average monthly mean temperatures at Kırşehir (MGM station 17160) confirms the value at that location reported by Güneş [19].

Unfortunately, the annual PET reported by Güneş [19] for several weather stations within and in the immediate vicinity of Seyfe basin exceeded annual precipitation in most years. This result is inconsistent with the stream discharge records in and adjacent to Seyfe basin. Actual evapotranspiration in the Seyfe basin must be significantly lower than the Güneş [19] estimate to support stream flow within the basin.

We made an estimate of actual annual evapotranspiration from daily stream discharge at two locations (Kalaycik stream at Doyduk (DSI station 
15-108) and Kılı̧̧özü stream above Çoğun Reservoir (DSİ station 15-152) using data for the period 1995-2012 [15]. Annual precipitation was based on daily precipitation recorded at Kırşehir (MGM 17160) for the same period for the purpose of making our annual potential evapotranspiration estimate.

We conclude actual evapotranspiration in Seyfe basin is roughly $70 \%$ of the potential evapotranspiration estimated using the Thornthwaite model. Kalaycık stream at Doyduk (DSİ statıon 15-108) and Kılıçözü stream above Çoğun Reservoir (DSİ statıon 15-152) are seasonal with zero discharge being recorded in several years during July, August, and September.

Çelik et al. [11] used oxygen-18 and deuterium isotope analysis to conclude all the Seyfe basin groundwater they studied has a meteoric origin. Çelik et al. [11] estimated a Thormthwaite PET of $32.0 \mathrm{~cm}$ using data form the MGM station 17160, a much lower value than Güneş [19]. Our hydrologic AET estimate is consistent with seasonal discharge of basin streams and, we believe, a more realistic estimate of soil water loss in the basin.

\subsection{Groundwater Salinity of the Seyfe Basin}

Table 2 lists the mean salinity of the wells included in this study, as recorded for the period 2006 to 2019. Data from several of these same wells also appeared in the recent study of Seyfe Basin groundwater [11]. The wells studied by Çelik et al. [11] were located roughly along the Akpınar Fault that lies to the west of Seyfe Lake. The wells included in this study include several that lie north of Seyfe Lake.

Table 2 reveals groundwater salinity ranges from a low of $340 \mu S \mathrm{~cm}^{-1}$ at Geycek (Mucur County) located immediately south of Seyfe Lake, to salinity levels of $2400 \mu \mathrm{S} \mathrm{cm} \mathrm{cm}^{-1}$ at Çamalak (Boztepe County) and $10000 \mu \mathrm{S} \mathrm{cm} \mathrm{cm}^{-1}$ at Karaarkaç (Mucur County), both located north of Seyfe Lake. The latter two wells were not included in the groundwater study of Çelik et al. [11].

Seyfe Lake is sustained by groundwater discharge from the entire Seyfe basin; therefore, we should anticipate a clear link between the chemistry of Seyfe Lake and the groundwater of the basin. The following section, however, will reveal a key chemical signature of most wells included in both this study and that of Çelik et al. [11] do not agree with the chemical signature of Seyfe Lake.

\subsection{Irrigation Water Quality of the Seyfe Basin}

Seyfe Lake is a closed-basin lake that owes its chemical signature to salinization by evaporative water loss. According to Hardie and Eugster [20], the 
Table 2: Mean and 95\% confidence interval for electrical conductivity for water samples drawn from groundwater wells in the Seyfe Basin. Well locations are identified by UTM coordinates in Zone 36S. Numbered wells are maintained by the State Hydraulic Works DSİ, located on Malya State Farm (Malya Tarım İ̧sletmeleri Genel Müdürlüğü).

Well (District)

Electrical Conductivity UTM Easting UTM Northing

$$
\mu S \mathrm{~cm}^{-1}
$$

$m$

$m$

Geycek (Mucur)

Boztepe (Boztepe)

Boztepe (Boztepe)

Budak (Mucur)

Yeniyapan (Hacıbektaş)

Çağşak (Kozaklı)

Seyrek (Merkez)

Üçkuyu (Boztepe)

Gümüşü̈mbet (Mucur)

DSI Malya 10769 (Boztepe)

DSİ Malya 14219 (Boztepe)

DSİ Malya 10764 (Boztepe)

DSİ Malya 10766 (Boztepe)

DSİ Malya 10767 (Boztepe)

Çamalak (Boztepe)

Karaarkaç (Mucur)

$\begin{array}{cr}340 \pm 10 & 629043 \\ 370 \pm 20 & 608295 \\ 400 \pm 10 & 608194 \\ 400 \pm 20 & 627380 \\ 480 \pm 60 & 633958 \\ 490 \pm 30 & 649288 \\ 500 \pm 100 & 609811 \\ 600 \pm 100 & 611238 \\ 630 \pm 50 & 614749 \\ 1,300 \pm 100 & 615829 \\ 1,400 \pm 100 & 615848 \\ 1,500 \pm 100 & 616448 \\ 1,600 \pm 200 & 615856 \\ 1,900 \pm 300 & 615901 \\ 2,400 \pm 300 & 633900 \\ 10,000 \pm 10,000 & 635105\end{array}$

4330958

4348753

4348342

4332517

4321045

4325652

4366017

4367450

4336807

4350759

4350759

4351626

4350776

4350789

4360211

4345794 
composition of every closed-basin lake evolves through the evaporative salinization of the water discharged into the lake. Hardie and Eugster [20] identify six distinct salinization pathways defined by major ion ratios at three chemical divides. The defining chemistry of Seyfe Lake is determined by the calcite chemical divide and the alkalinity-to-calcium molar ratio of the groundwater that discharges into the Lake.

\subsection{Groundwater Alkalinity of the Seyfe Basin}

The salinization chemistry of Seyfe Lake is determined by the alkalinityto-calcium molar ratio of the groundwater that discharges into the Lake. Figure 2 shows calcite solubility in Seyfe Lake by plotting water analysis calcium and alkalinity. The calcite chemical divide is the vertical line passing through the point where the alkalinity-to-calcium mole ratio is unity (and the logarithm of the ratio is zero). The alkalinity-to-calcium mole ratios in Seyfe Lake are less than unity, falling to the left of the calcite chemical divide in Figure 2. This means increasing salinization through lake surface evaporation will drive lake water Alk/Ca ratios to values that are ever lower and dissolved calcium levels ever higher.

Figure 3 shows most water samples from Seyfe Lake are near gypsum saturation. This confirms the brine in Seyfe Lake has crossed the calcite chemical divide and progressed to the gypsum chemical divide by following a salinization pathway that removes alkalinity faster than calcium because the $\mathrm{Alk} / \mathrm{Ca}$ mole ratio of the water is less than unity. The results in Figure 3 confirms the salinization pathway for Seyfe Lake.

Figure 2 reveals the low and medium salinity $\left(300 \mu S \mathrm{~cm}^{-1}<E C<\right.$ $2000 \mu S \mathrm{~cm}^{-1}$ ) wells in Seyfe Basin, which discharge into Seyfe Lake, plot to the right of the calcite chemical divide (cf. filled circles) indicating the groundwater in these wells will follow a different salinization pathway than indicated by samples from Seyfe Lake. Once groundwater represented by the filled circles in Figure 2, i.e., groundwater whose Alk/Ca mole ratio is greater than unity (and whose logarithm of the ratio is greater than zero), discharges into Seyfe Lake and undergoes evaporative salinization, it will trend toward higher alkalinity and lower dissolved calcium. The salinization pathway for the filled circles in Figure 3 will trend further to the right as it follows the calcite solubility line. Figure 3 also reveals the chemical signature of Seyfe Lake brine and chemical signature of most wells in Seyfe basin are fundamentally different. The salinization pathway identified by Hardie and 


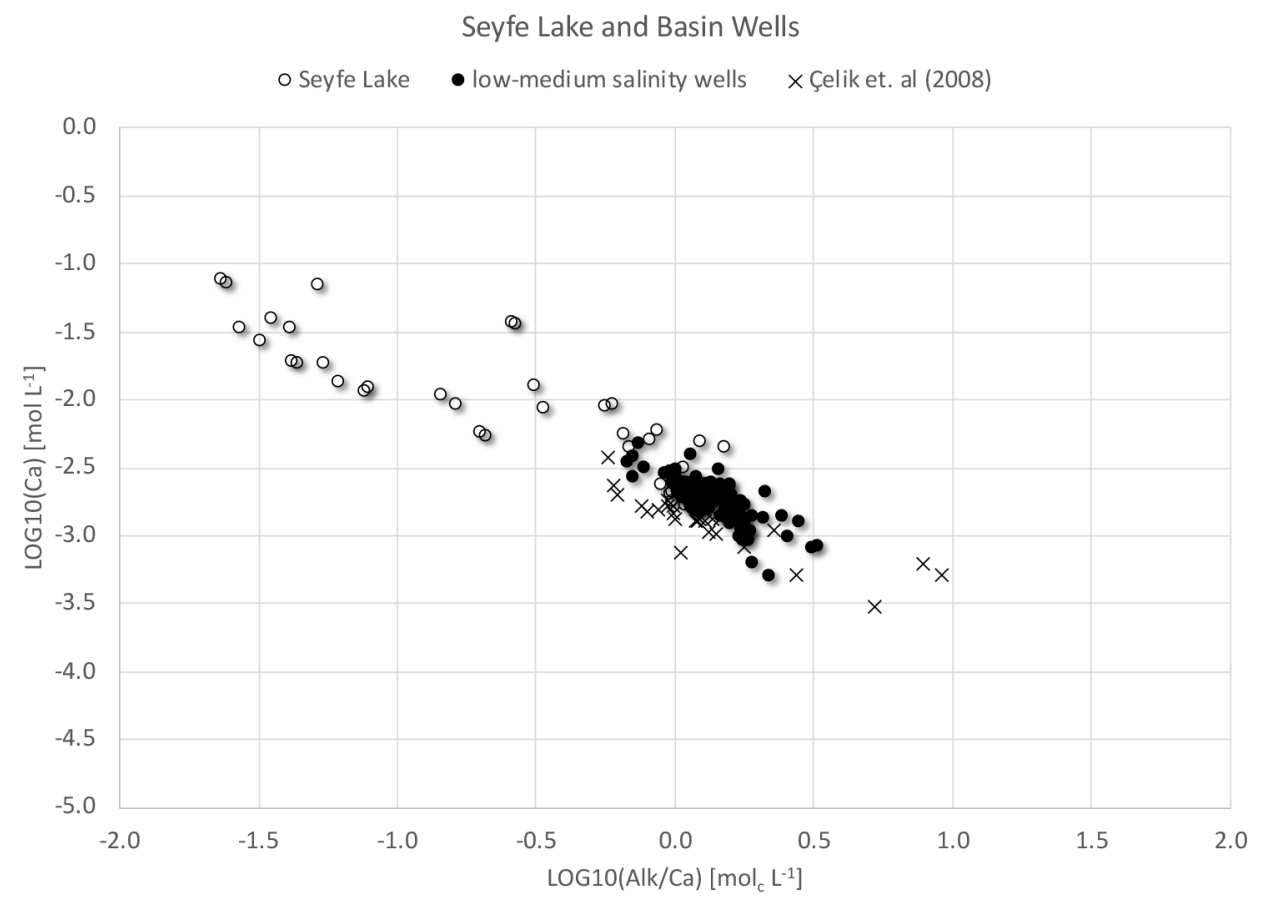

Figure 2: A plot of $\mathrm{CaCO}_{3}(\mathrm{~s})$ calcite solubility for Seyfe basin water samples reveals calcite saturation. All data points are based on total dissolved calcium TOT(Ca) and alkalinity $\mathrm{TOT}\left(\mathrm{HCO}_{3}\right)$ : Seyfe Lake sanples (open circles), low-to-medium salinity wells (filled circles) and well data from [11] (× symbols). 


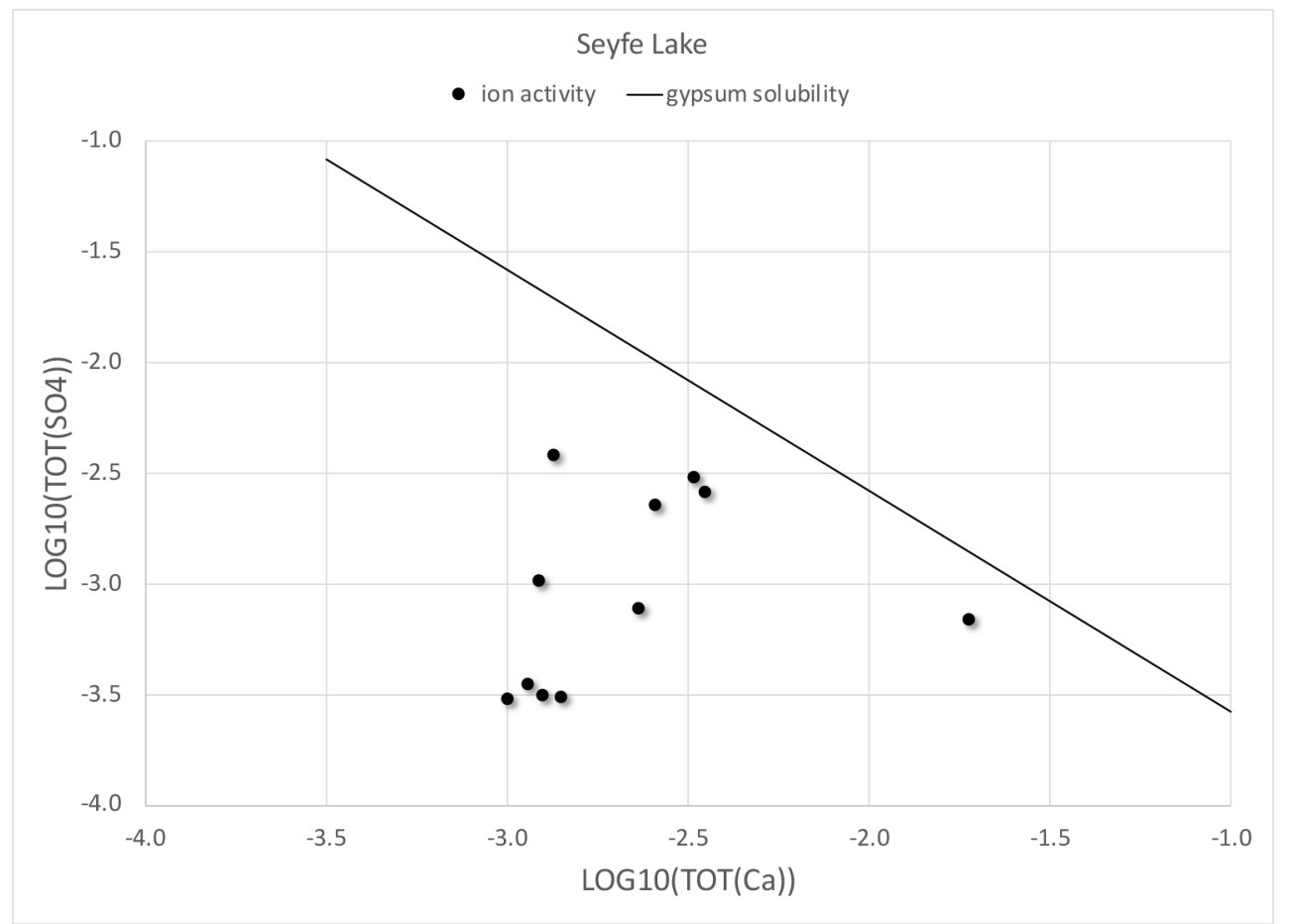

Figure 3: A plot of $\mathrm{CaSO}_{4} \cdot \mathrm{H}_{2} \mathrm{O}(\mathrm{s})$ gypsum solubility for Seyfe Lake water samples. The data points are based on total dissolved calcium $\mathrm{TOT}(\mathrm{Ca})$ and sulfate $\mathrm{TOT}\left(\mathrm{SO}_{4}\right)$. The gypsum chemical divide at $\log _{10}\left(\mathrm{SO}_{4}\right)=\log _{10}(\mathrm{Ca}) \approx-2.5$ 
Eugster [20] for groundwater that will ultimately discharge into Seyfe Lake is different from the salinization pathway followed by the lake water.

Çelik et al. [11] relied on Schoeller, Piper, and Wilcox diagrams to reveal the chemical characteristics of Seyfe Basin groundwater. None of these diagrams reveal the salinization pathway the groundwater sources in Seyfe Basin will follow during evaporative water loss.

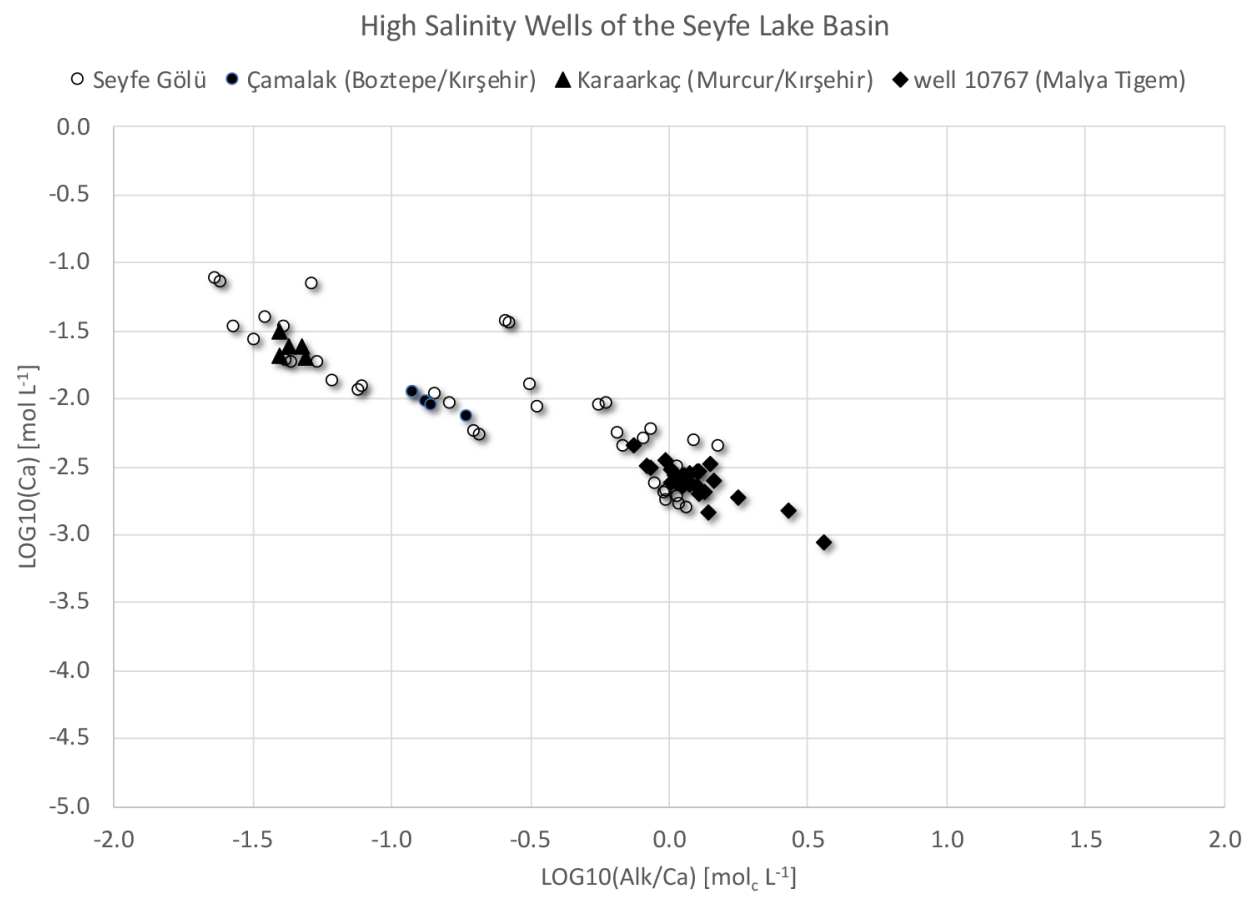

Figure 4: A plot of of $\mathrm{CaCO}_{3}(\mathrm{~s})$ calcite solubility for Seyfe basin water samples. All data points are based on total dissolved calcium TOT $(\mathrm{Ca})$ and alkalinity $\mathrm{TOT}\left(\mathrm{HCO}_{3}\right)$ : Seyfe Lake sanples (open circles) and three high salinity wells (DSI well 10767 (filled diamonds), an unnumbered DSI well near Çamalak (filled circles), and an unnumbered DSİ well near Karaarkaç (filled trianges)). The calcite chemical divide is the vertical line through $\log _{10}\left(\mathrm{HCO}_{3} / \mathrm{Ca}\right)$ equal to zero.

This study includes the chemical analyses of three high-salinity wells from Seyfe Basin: well 10767 located on the Malya Government Farm (Malya Tarım İşletmesi Genel Müdürlüğü) $5 \mathrm{~km}$ north of Seyfe Lake (designated well T6 in Çelik et al. [11], a second well near Çamalak (Boztepe County) and third well near Karaarkaç (Mucur County). The latter two wells lie at the northern edge of Seyfe Basin and slightly north of the eastern edge of 
Seyfe Lake, respectively. Calcite solubility for these three wells appear in Figure 4. Please note Çelik et al. [11] includes a single analysis of well 10767 (designated well T6) dating from 2003 while the present study includes 25 analyses from 2006 to 2019.

The data from the present study for DSI well 10767 falls in the same range as the earlier results from Çelik et al. [11], namely to the right of the calcite chemical divide in Figure 4 . This is in the same range as the results from low and medium salinity wells. Groundwater from well 10767 will follow an alkaline salinization pathway under evaporative water loss. The alkaline salinization pathway is inconsistent with the neutral (i.e., low alkalinity) pathway for Seyfe Lake as shown in Figure 2 and Figure 4.

The data from the other two high salinity wells, located near Çamalak (Boztepe County) and near Karaarkaç (Mucur County), plot to the left of the calcite chemical divide in Figure 4. Groundwater from wells located at Çamalak and Karaarkaç will follow a neutral salinization pathway under evaporative water loss, consistent with the chemical signature of Seyfe Lake.

The results in Figure 5 and Figure 6 are further evidence that high salinity groundwater sampled in the wells located at Çamalak and Karaarkaç are dramatically different from the other wells included in this study. Consistent with the results plotting to the left of the calcite chemical divide in Figure 4, increasing salinity is associated with consistently low alkalinity (Figure 5) and much higher dissolved calcium (Figure 6) relative to the groundwater found in most Seyfe Basin wells.

\section{Discussion}

The brine in Seyfe Lake has clearly passed the Hardie-Eugster calcite chemical divide (Figure 2) and appears to be poised at the gypsum chemical divide (Figure 3). An alkalinity-to-calcium molar ratio less than unity is needed for salinization by evaporative water loss at the lake surface to lead from the calcite chemical divide to the gypsum chemical divide. Figure 2 and Figure 3 demonstrate this condition has been met.

Samples drawn from low and medium salinity wells and one (i.e., well 10767) high salinity groundwater well in Seyfe Basin reveal an alkalinityto-calcium molar ratio greater than unity (Figure 2 and Figure 4). We can reasonably assume these groundwaters-whose chemical signatures are plotted as filled circles in Figure 2-are the principal source of water discharged into Seyfe Lake. This being the case, evaporative salination of the groundwater 


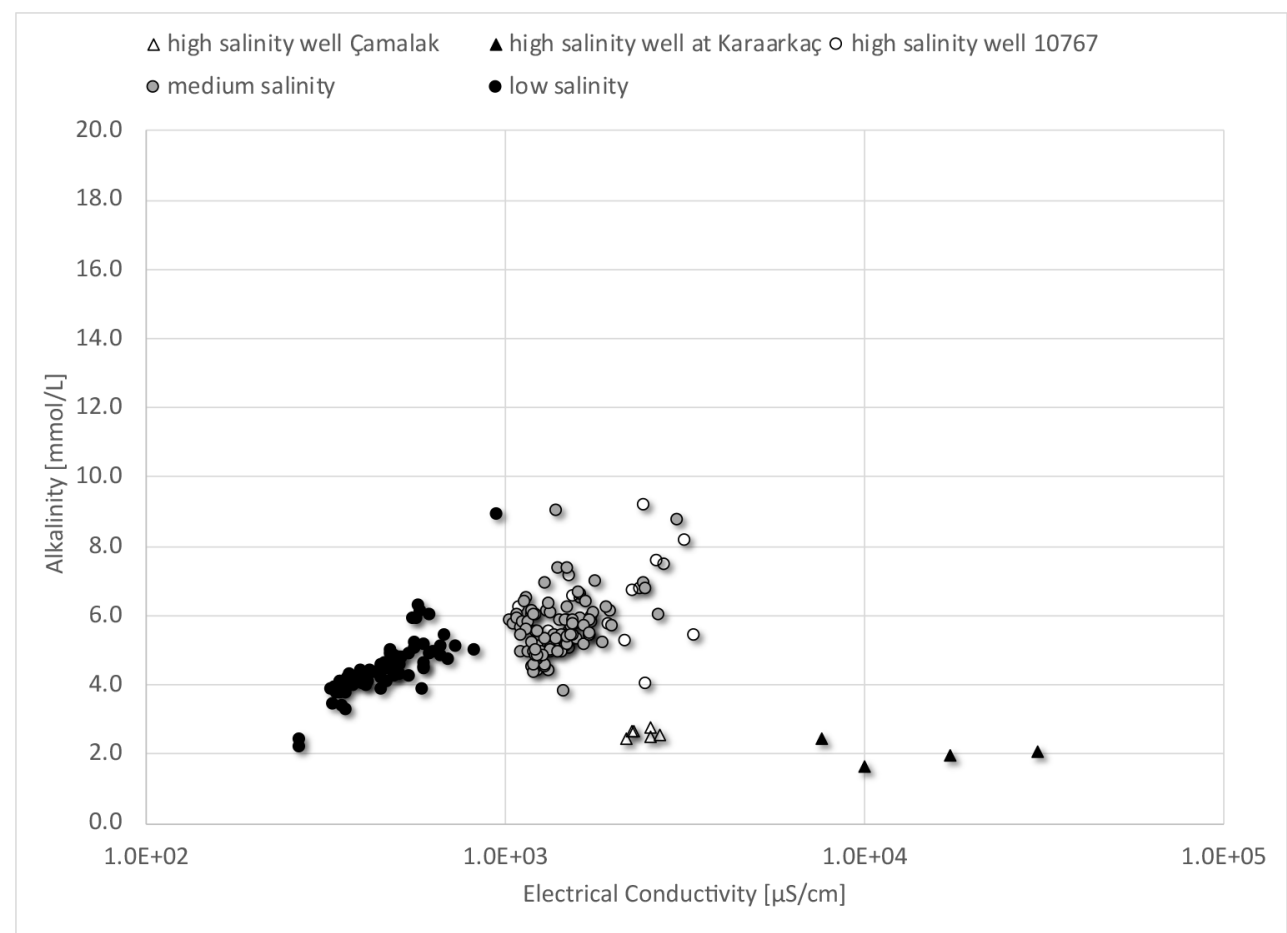

Figure 5: A plot of total dissolved alkalinity $\mathrm{TOT}\left(\mathrm{HCO}_{3}\right)$ as a function of electrical conductivity for low (black filled circles), medium (grey filled circles) and high (open circles) salinity wells in Seyfe Basin. Results from a high salinity well near Çamalak are plotted as open triangles while results from a high salinity well near Karaarkaç are plotted as filled triangles. 


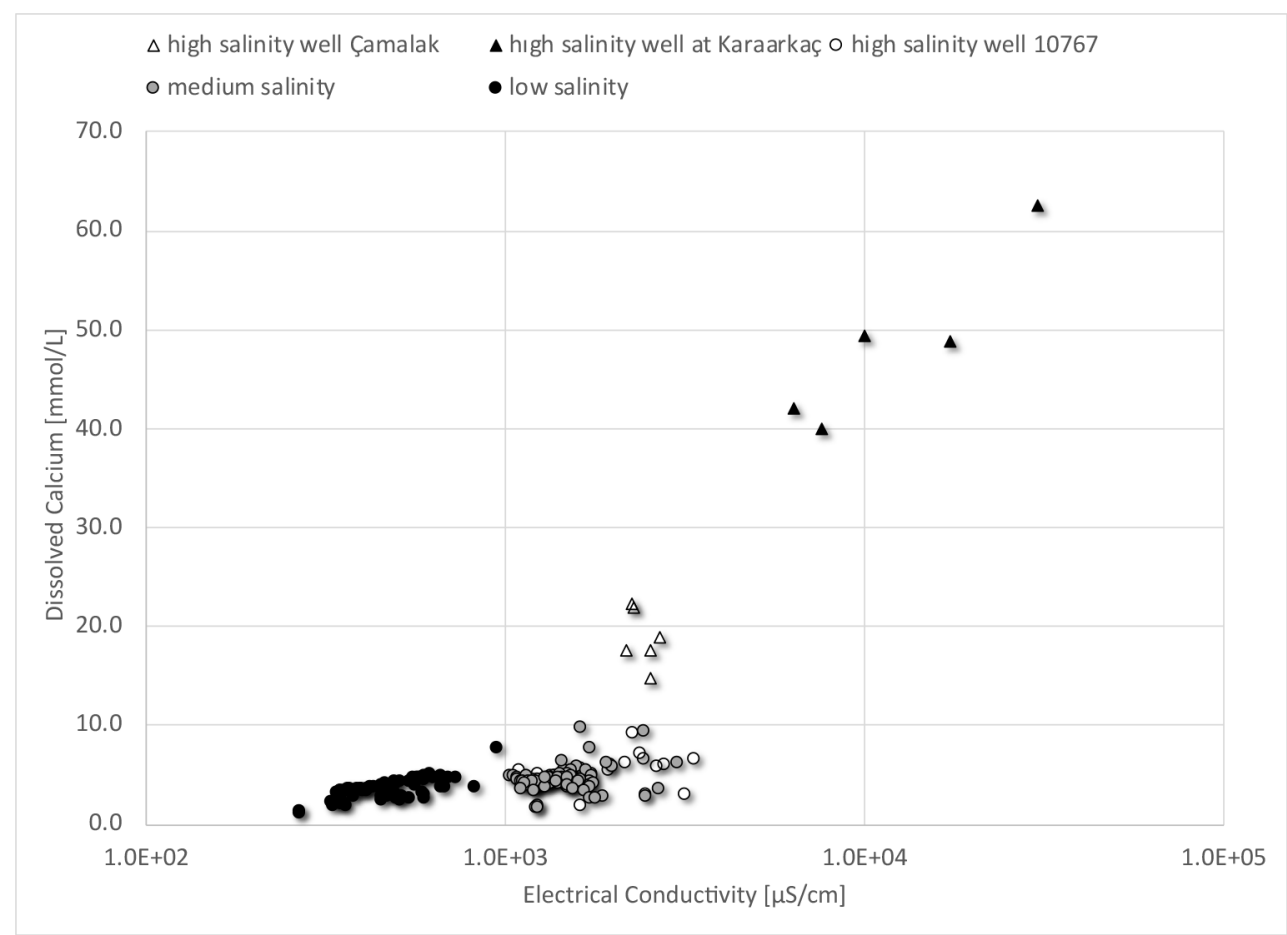

Figure 6: A plot of total dissolved calcium $\mathrm{TOT}(\mathrm{Ca})$ as a function of electrical conductivity for low (black filled circles), medium (grey filled circles) and high (open circles) salinity wells in Seyfe Basin. Results from a high salinity well near Çamalak are plotted as open triangles while results from a high salinity well near Karaarkaç are plotted as filled triangles. 
found in most wells within Seyfe Basin cannot explain the results in Figure 2 and Figure 3.

We suggest a rationale that can reconcile these groundwater results with the low alkalinity and high dissolved calcium of Seyfe Lake. Saline groundwater of the type found in the wells at Çamalak and Karaarkaç contain high levels of dissolved calcium (Figure 6) that may be sufficient precipitate the alkalinity discharged into Seyfe Lake from the low and medium salinity groundwater typical of the more numerous wells in Seyfe Basin (Figure 5). We suggest the groundwater discharged into Seyfe Lake results from a mixing of two very different groundwater sources.

Our proposed rationale requires a highly saline, calcium-rich groundwater (Figure 6) to counter-balance the alkalinity from the presumably more widespread, low calcium, alkaline groundwater discharging into Seyfe Lake. We have no evidence that saline groundwater passing Çamalak is the same source passing Karaarkaç, although the results in figure Figure 5 and ?? suggest this may be the case. It is worth noting the two locations are roughly aligned along a potential flow path that leads from the vicinity of Çamalak to a discharge point into Seyfe Lake near Karaarkaç.

\section{Conclusion}

Çelik et al. [11] concluded evapotranspiration in Seyfe Basin is much higher than infiltration. Streams in Seyfe Basin are seasonal with monthly AET exceeding precipitation in most years during July-September and groundwater recharge during the remaining nine months. We found no evidence of groundwater salinization based on data provided by DSİ but anticipated climate change (lower precipitation and higher temperatures) has clear implications for future irrigation demand in the basin and the potential for groundwater salinization.

The state production farm near Boztepe, Malya TIGM, does not report leaching ratios for the groundwater sources used for irrigation. It is uncertain whether current leaching ratios need to be adjusted under the likely climate change scenario. Malya TIGM also does not report the salinity of irrigated soils. Absent access to soil salinization records, it is impossible to predict how rapidly soil salinity may develop under climate change at Malya TIGM and other irrigated land of the basin.

Given the high Alk/Ca ratio shown in Figure 4, most of the basin groundwater is on the alkaline side of the calcite chemical divide. Applying ground- 
water with this chemical signature will lead to greater soil alkalinity as salinization develops. Depending on the clay content and clay mineralogy of basin soils, there is a risk for developing soil sodicity from irrigating with groundwater whose Alk/Ca ratios are greater than unity.

\section{Acknowledgements}

[to be written]

\section{References}

[1] T Xu et al. "Wetlands of international importance: Status, threats, and future protection". In: International Journal of Environmental Research and Public Health 16.10 (2019), p. 1818.

[2] W J Mitsch. Global Wetlands: Old World and New. Amsterdam (Netherlands) Elsevier, 1994.

[3] M M Brinson and A I Malvárez. "Temperate freshwater wetlands: types, status, and threats". In: Environmental Conservation 29.2 (2002), pp. 115133.

[4] C Finlayson. "Forty years of wetland conservation and wise use". In: Aquatic Conservation: Marine and Freshwater Ecosystems 22.2 (2012), pp. 139-143.

[5] R C Gardner et al. State of the world's wetlands and their services to people: A compilation of recent analyses. 2015. URL: https : / / papers.ssrn.com/sol3/Delivery.cfm/SSRN_ID2589447_ code623498.pdf?abstractid=2589447\&mirid=1.

[6] R C Gardner and C Finlayson. "Global wetland outlook: state of the World's wetlands and their services to people". In: Ramsar Convention Secretariat. 2018, pp. 2020-2025.

[7] C Yurteri. "Hydrogeological and Hydrochemical Evaluation of Water Resources in Seyfe Lake (Mucur-Kırşehir) Wetland Basin". In: Dokuz Eylül Üniversitesi Mühendislik Fakültesi Fen ve Mühendislik Dergisi 22.65 (2020), pp. 581-597. URL: https : / / papers. ssrn . com / sol3/Delivery. cfm/SSRN_ID2589447_code623498.pdf ? abstractid=2589447\&mirid=1. 
[8] R Smardon. Sustaining the World's Wetlands: Setting Policy and Resolving Conflicts. Springer Science \& Business Media, 2009.

[9] S G Kim. "The evolution of coastal wetland policy in developed countries and Korea". In: Ocean $\&$ Coastal Management 53.9 (2010), pp. 562 569.

[10] Bolat S. "Investigation of degree of pollution of the soil and water on Seyfe Lake and their neighborhood [Translated Title]". Turkish. Masters of Science thesis. Gazi Üniversitesi, 2006.

[11] M Celik et al. "Assessment of water quality and pollution of the Lake Seyfe basin, Kırşehir, Turkey". In: Environmental Geology 55.3 (2008), pp. 559-569.

[12] S Kiymaz and U Karadavut. "Application of multivariate statistical analysis in the assessment of surface water quality in Seyfe Lake, Turkey". In: Journal of Agricultural Sciences 20 (2014), pp. 152-163.

[13] S Kiymaz. "Water resources management of Seyfe Lake wetlands and recommendation for resolve". In: Journal of New World Sciences Academy 5.2 (2010), pp. $174-186$.

[14] M Türkeş. "Climate of southern part of the Middle Kizılırmak SubRegion (Cappadocia District) and its vulnerability to desertification". In: Aegean Geographical Journal 14.4 (2005), pp. 73-97.

[15] General Directorate of State Hydraulic Works]. DSI Flow Observation Annuals (1959-2015). https://www.dsi.gov.tr/Sayfa/ Detay/74 4. n.d.

[16] L S Clesceri, A D Eaton, and A E Greenberg. Standard Methods for the Examination of Water and Wastewater. 20th. Washington, DC: American Public Health Association, American Water Works Association, Water Environment Federation, Water Pollution Control Federation, 1998.

[17] Nilgun B Harmancioglu and Dogan Altinbilek. Water Resources of Turkey. Springer, 2020.

[18] C W Thornthwaite. "An approach toward a rational classification of climate". In: Geographical Review 38.1 (1948), pp. 55-94. 
[19] V Guneş. Climate of Kirşehir, Nevşehir, Aksaray. 2009. URL: https: //papers.ssrn.com/sol3/Delivery.cfm/SSRN_ID2589447_ code623498.pdf?abstractid=2589447\&mirid=1.

[20] L A Hardie and H P Eugster. "The evolution of closed basin brines". In: Mineralogical Society of America Special Papers 3 (1970), pp. 273-290. 